\title{
The Impact of Intrinsic and Extrinsic Motivators on IT professionals. Case of Latvia.
}

\author{
Svetlana Gribanova ${ }^{1, *}$ \\ ${ }^{1}$ Turiba University, Latvia
}

\begin{abstract}
.
Research background: In contemporary environment and conditions of globalization, IT professionals become significant part of labour force for every organization, which needs to be competitive in the market. This paper, on one hand, demonstrates how employees can be involved in production process, and, on the other hand, it helps to observe the interconnection between theory and practical application of management.

Purpose of the article: The purpose of the research was in defining and determining the influence of intrinsic and extrinsic motivators for IT professionals in Latvia.

Methods: The data for the research was collected with the help of online survey held in December 2019 using online survey panels. The targeting criteria for the respondents was the employment on position of IT employee, company located in Latvia and employed full time. Sample size was 1500 respondents. The research used factor analysis, which allowed defining intrinsic and extrinsic motivators and evaluating their significance and method of multidimensional linear regression to determine the influence of personal characteristics of employees on types of motivation.

Findings \& Value added: Factor analysis of motivations shows that there are five types of motivators, which make IT professionals work more productively, stay late at work if needed and do the best they can to solve the task set by their management. These are material stimulators, respect, responsibility, fear and self-realization. The results of the research can be well interpreted with the help of McGregor Theory, who demonstrated that there is a need of combination of extrinsic and intrinsic motivators. The findings can be used in building appropriate motivation strategy for IT professionals.
\end{abstract}

Keywords: Intrinsic motivation; extrinsic motivation; IT professionals; factor analysis; regression

JEL Classification: M15; M12; M54; O15

\footnotetext{
*Corresponding author: svetlana.gribanova.p@gmail.com
} 


\section{Introduction}

In the management theories, motivation is observed as a driving force of participation in any kind of activity. Numerous research papers demonstrate that except satisfaction from work, contemporary professional employees, including IT professionals, are driven towards achieving work-life balance. These findings allow assuming that contemporary professionals are motivated with various factors their job offers, and sometimes these factors are not obvious.

There are various levels and ways of motivation, which play significant part in determination how strong employee is motivated [1,2]. For example, employees can have high motivation in completing certain project, connected with gaining professionals skills, which are necessary to finish the task successfully. However, part of this group can be additionally motivated by the willingness to demonstrate to their colleagues that they are qualified enough, that they have enough knowledge and skills, to complete challenging projects. Additionally, another group foresees the accomplishment of the task as an opportunity for promotion and salary increase as the strongest motivator. Despite the fact that both these groups are motivated, they are motivated by different factors. It is significant to understand which factors define the motivation of the employees and the reasons of it; which factors can become driving force for more productive performance and which interfering activities from managers can become necessary for solving internal tasks of the companies, which employ IT professionals. IT professionals Latvia are part of the global world. In the context of globalization, the job satisfaction and motivation to work of IT employees is of particular importance.

There is no general formula for creating universal attractive management model by combining theoretical and practical approaches. This paper, on one hand, demonstrates how employees can be involved in production process, and, on the other hand, it helps to observe the interconnection between theory and practical application of management.

\section{Review of Relevant Literature}

Motivation is multidimensional definition. It includes not only intrinsic and extrinsic characteristics, but it also depends on expectation of the employee personally. Despite the fact that sometimes extrinsic and intrinsic motivators can be observed and completely different approaches, these two categories can definitely be used in order to create effective working environment [3]. Understanding, which motivators work better in definite conditions, becomes key factor for the effective management of employee motivation bot on individual and corporate levels.

Management of organizations, operation in the market of Information Technologies, needs to develop strategies, which allow determining, which motivators work better for IT professionals in their unique conditions. In order to understand the concept of motivation theories for employees performing creative work, it is necessary to briefly observe basic theoretical definitions and directions, which explain, which factors influence productive work and allow increasing labor productivity

The principle of scientific management by Taylor [4] grounded on the facts that employees need to be under constant control and observation while they need to be motivated by material motivators. He supported fair pay for the employees and for the strict control and penalty scheme. Later Elton Mayo and his colleagues [5] came to the conclusion that social atmosphere and attentions for the employees influence labor productivity increase stronger than penalties. For the first time the conclusions about significance of psychological factors, which influence motivation such as autonomy of the employees, attention to social factors and solidarity, were made [6]. 
Model "Hierarchy of needs" built by Maslow [7] explained motivation based on satisfaction of different levels of needs including five categories: physiological needs and need for security could be satisfied by extrinsic factors, such as salary; self-realization, need for self-development and others could be satisfied by intrinsic factors of opportunities for professional and personal growth, social connection, autonomy and development [8].

This work survived the test of time. Nowadays, there is a number of researches, which use Maslow Theory for explanation and prediction of behavior in certain economic conditions, when labor productivity increases or decreases [9]. However, there is criticism of this theory that is useful to consider [10] conducted an analysis of the hierarchy of needs that Maslow proposed, and concluded that there was almost no evidence for this order of needs. Recognizing that persons really need to be satisfied, the existence of the order of needs for each person is called into question. Hofstede [11] relied on this premise, arguing that the hierarchy was immersed in ethnocentricity and based on Western ideology. Hofstede argues that Maslow's theory does not take into account differences in the cultural needs of societies and their unique social and intellectual needs. Cianci and Gambrel [12] criticized Maslow's theory as an oversimplified view of human needs. They argued that Maslow did not consider the needs of society at a particular time, such as an economic crisis or war. Also, studies by Tay and Diener [13] showed that the ranking of needs varies with age and does not appear to be the same in all age groups.

In the beginning of 1960-s numerous significant researches in the field of motivation were done and various theories were formulated including McGregor Theory [14] and Vroom Expectancy Theory [15], which tried to solve the mystery of motivation and its influence of organization behavior. Vroom Theory gives and explanation why people choose certain behavior and how it is connected with their expectations. The theory explains psychological and cognitive processes, which individual experience, when making choice.

Theory X and Theory Y of McGregor assumed that average workers do not like their job. That is why the only way to keep certain level of labor productivity is to ease the working process, control employees and motivate them in a short-term perspective $[14,16]$. Theory $\mathrm{X}$ assumed that employees are lazy, that they avoid responsibility and do not like the work they do, while Theory Y assumed that average employees are capable of self-control and want responsibility. Various scholars either confirmed or rejected either Theory X or Theory $\mathrm{Y}[17,18]$. However, it is significant to recall, that such dichotomy exists, and understand close connection between these theories, between intrinsic and extrinsic motivation of employees in a workplace.

Intrinsic motivation is determined as «doing of an activity for its inherent satisfactions rather than for some separable consequence» [1, p. 56] or «performing an activity for the pleasure inherent in the activity [19, p. 707], but not for reward or appraisal. In other papers a Ryan and Deci found that «intrinsic motivation makes an individual much more likely to be motivated and perform well as opposed to those that were extrinsically motivated» [20]. In fact, those who we familiar with intrinsic motivation, were less motivated by material motivators. In such a way, intrinsic motivators are feeling of satisfaction, which employees get completing significant tasks, especially when the job is well done.

Extrinsic motivation is determined as «doing something because it leads to a separable outcome» [21]. This can be some kind of appraisal or reward (mostly, material), but not a feeling of satisfaction from work. This motivation is called extrinsic because the means of this type of motivation are extrinsic in relation to job or employee. They are set and controlled by other individuals. The amount of reward is also determined by decisions of others. Money is not the only extrinsic motivator, but also job security, promotion etc. [21]. There are researches which demonstrate that some extrinsic motivators, such as career growth, can lead to increase of intrinsic motivation, but the motivation stay extrinsic [22]. 
Concepts of intrinsic and extrinsic motivators are significant not only for individual labor productivity, but also they play important part and influence labor productivity of the whole team, working on a project and organization in general. That is why they require special attention and research. Creating of attractive job positions, which correspond with values of the employees and are created for autonomy, self-development, personal and professional growth, is of special significance for companies, working in IT. This market is characterized by high demand for professionals, and company success depends on the willingness of these professionals to cooperate to higher extent.

Criticizing the two factor theory, Deci and Ryan opposed the unified construct of motivation. Instead, they stated that motivation is either autonomous or controlled [20]. Autonomous motivation refers to the types of motivation that involve internal processes through which people come to the definition and assimilation of the value of activities, while controlled motivation refers to the types of motivation that are the result of external requirements. Thus, it seems that autonomous motivation seems to be consistent with our idea of internal achievement motivation, while controlled motivation is similar to external achievement motivation.

Employees who seek to achieve external results-oriented goals are concerned that their productivity will be higher than others [21]. Internally motivated employees use more complex cognitive strategies than do externally motivated ones [22]. It was found that employees who love their work are focused on competitiveness and on the development of their knowledge and skills.

Critics of the theory of external and internal motivations argue that such a separation is false [22]. They are convinced that external motivation does not exist. All motivation comes from intrinsically valued goals common to everyone and deeply rooted in human nature. Investigating a person's motivation for a certain activity, it is better to analyze individual causes, rather than trying to qualify them and divide them into two types [21].

Short literature review demonstrates, that employees are motivated by synergy of factors, including values, expectations and principles [17, 22]. A number of researches demonstrate, that intrinsic motivators overcompensate lack of extrinsic motivators, that is why extrinsic motivators are under estimated in some cases [19].

Despite the assumption, that extrinsic motivation can be foreseen as not very significant comparing to intrinsic motivation, this research is targeted to show that the ability to find the perfect balance between these two types of motivation is and art of management, which can lead to positive results.

\section{Methods}

The goal of the research was in defining and determining the influence of intrinsic and extrinsic motivators for IT professionals in Latvia. The data for the research was collected with the help of online survey held in December 2019 using online survey panels. The targeting criteria for the respondents was the employment on position of IT employee, company located in Latvia and employed full time. Sample size was 1500 respondents. Average age - 38. Age group up to $30-19 \%$, 30 to $40-40 \%$, 40 to 50 лет - 26\% and older than $50-15 \% .77 \%$ - males, $23 \%$ - females.

During the survey respondents had to reply the questions, identifying influence of motivation factors. The respondents had to choose the factors, which encourage them to work more productively. There were following motivators in the list: High salary, Interesting creative task, Chance for promotion, Clarity and preciseness of the goals and result, High significance, prestige of the task, Respect from the team, Approval from the management, Crisis situation, understanding of responsibility, Fear of dismissal or bonus reduction, Fear of disapproval from colleagues and management 
The responses received were analyzed with the help of factor analysis, which allowed defining intrinsic and extrinsic motivators and evaluating their significance. The significance of these motivators were analyzed separately for various age groups (ANOVA Test) and for male and female respondents (T-Test for two independent samples).

Significant task of the research was to find the dependency between types of motivations and characteristics of employees. As employee characteristic, despite age and gender, there were such characteristics as existence of the partner, respondent's income (subjective evaluation), location either in the capital or other cities, migration status (born in Latvia or other country), official duties (technical tasks, creation of the products, problem solving tasks and process optimization). The method of multidimensional linear regression was used to determine the influence of personal characteristics of employees on types of motivation.

\section{Results}

Factor analysis of motivations demonstrated in Table 1 shows that there are five types of motivators, which make IT professionals work more productively, stay late at work if needed and do the best they can to solve the task set by their management.

Table 1. Factor loadings of motivators (intrinsic and extrinsic motivators)

\begin{tabular}{|l|c|}
\hline \multicolumn{1}{|c|}{ Item } & Factor loadings \\
\hline Material stimulators (factor 1) & 0,76 \\
\hline High material reward & 0,65 \\
\hline Chance for promotion & 0,72 \\
\hline Fear (factor 2) & 0,73 \\
\hline Fear of dismissal or bonus reduction & 0,69 \\
\hline Fear of disapproval from colleagues and management & 0,78 \\
\hline Respect (factor 3) & \\
\hline Respect from the team & 0,56 \\
\hline Approval from the management & 0,89 \\
\hline Self-realization (factor 4) & \\
\hline Interesting creative complicated task & 0,54 \\
\hline High significance, prestige of the task & 0,64 \\
\hline Responsibility (factor 5) & \\
\hline Clarity and preciseness of the goals and result & \\
\hline Crisis situation, understanding of responsibility &
\end{tabular}

It is possible to refer Factor 1 and Factor 2 to extrinsic motivators. Despite fear being an intrinsic feeling, it is caused by extrinsic factors (actions from management) and grounded by unsatisfied need of security, which is basic motivation by Maslow. In such a way, factor 1 can be called positive extrinsic motivator and factor 2 can be called negative extrinsic motivator.

Factors 3,4, and 5 describe intrinsic motivation. They are connected with the need of belongingness to the group (factor "responsibility"), trust (factor "respect") and selfactualization (factors "self-realization).

Figure 1 demonstrates distribution of motivators for IT professionals in Latvia. The data shows that almost $45 \%$ of IT professionals can be motivated with the help of providing them opportunity for self-realization, meaning giving them opportunity for participation in challenging projects and solving complex tasks. Material reward and career perspectives are attractive for $23 \%$ of respondents. Understanding personal responsibility and significance of the job IT professionals are performing motivate almost same amount of respondents, $21 \%$. The difference between these motivators is less that measurement error for the sample size, $2,5 \%$. 
The motivator for respect from the team and approval from management is not so familiar for IT professionals. This factor motivates only $10 \%$ of respondents. The fear of dismissal is not effective at all as less than $2 \%$ of respondents worked better in the situation of being under pressure of losing their job.

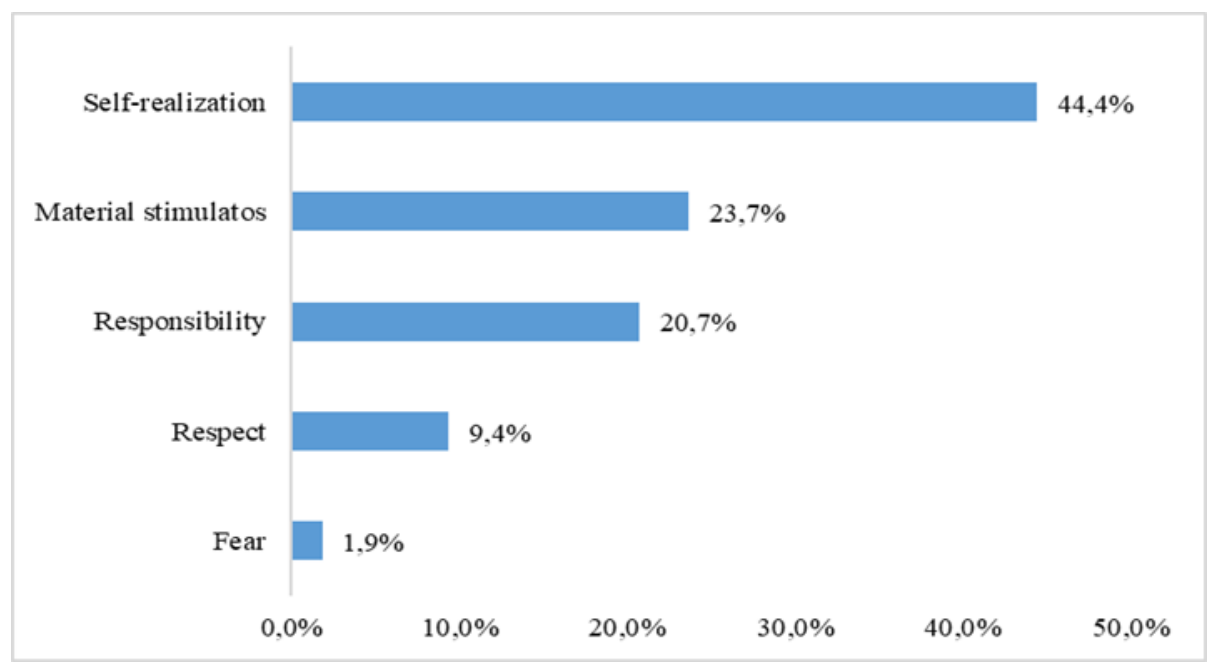

Fig. 1. Motivator distribution

Table 2 demonstrates results of ANOVA test, which shows the differences in mean values between age groups. From this data it is visible that the difference between age groups exist only in "Material stimulation" and "Respect" motivators. These ways of motivation better influence the employees aged up to 30 . It is worth to mention that T-test showed absence of differences in motivation for male and female respondents. .

Table 2. ANOVA test results. Differences of mean value of motivators in age groups.

\begin{tabular}{|c|c|c|}
\hline Motivator & F- criteria & P-value \\
\hline Material stimulators & 2,9 & $0,031^{* * *}$ \\
\hline Respect & 4,1 & $0,006^{* * *}$ \\
\hline Responsibility & 0,3 & 0,799 \\
\hline Fear & 0,8 & 0,486 \\
\hline Self-realization & 1,004 & 0,399 \\
\hline$* *$ - p-value $<0,05$ &
\end{tabular}

In order to create effective model of management it is significant to understand on which factors effectiveness of using motivators depends. In order to get answer to this question, this research used multiple regression analysis, which demonstrated connection of motivators with characteristics of IT professionals. The values of factors, received with the help of factor analysis, were used as dependent variables in regression analysis. In such a way, five regression models for each motivator were built.

Characteristics of IT professionals were independent variables: Age, measured in year. Gender (dummy variable, male=1). Place of living: capital (Riga) or other (dummy variable, riga $=1$ ). Migration status, meaning, born in Latvia (dummy variable, latvia=1). Having a partner (dummy variable, partner $=1$ ). Professional duties (3 dummy variables): Technical employee (technical_staff $=1$, reference variable). Duties: Service, System administration, code checking etc. Creative employee (creative_professional=1). Duties: Optimization of processing, improvement of codes. Super creative employee (super_creative_core=1). Duties: Creating new products (codes, programs), new approaches in completing tasks. 
Material state (10-points scale). Question: In the income scale where 1 means the lowest income level and 10 the highest in y our country, which level do you refer your income?

Table 3. Multiple regression analysis.

\begin{tabular}{|l|c|c|c|c|c|}
\hline & $\begin{array}{c}\text { Model 1. } \\
\text { Material } \\
\text { stimulation }\end{array}$ & $\begin{array}{c}\text { Model 2. } \\
\text { Respect }\end{array}$ & $\begin{array}{c}\text { Model 3. } \\
\text { Responsi } \\
\text { bility }\end{array}$ & $\begin{array}{c}\text { Model 4. } \\
\text { Fear }\end{array}$ & $\begin{array}{c}\text { Model 5. } \\
\text { Self-realization }\end{array}$ \\
\hline Constant & 0,143 & 0,05 & $0,305^{* * *}$ & 0,264 & $-0,402^{* * *}$ \\
\hline Age & $-0,008^{* * *}$ & $-0,008^{* * *}$ & $-0,001$ & $-0,004$ & 0,003 \\
\hline $\begin{array}{l}\text { Gender } \\
\text { (male=1) }\end{array}$ & $-0,145^{* * *}$ & 0,026 & $-0,109$ & 0,007 & 0,018 \\
\hline riga=1 & 0,035 & $-0,071$ & 0,01 & 0,031 & $-0,144$ \\
\hline partner=1 & $0,257^{* * *}$ & $-0,064$ & 0,022 & 0,009 & 0,020 \\
\hline latvia=1 & 0,092 & 0,012 & 0,043 & $-0,106$ & 0,013 \\
\hline $\begin{array}{l}\text { creative } \\
\text { professional=1 }\end{array}$ & 0,081 & $0,116^{* * *}$ & $0,163^{* * *}$ & $-0,033$ & $0,275^{* * *}$ \\
\hline $\begin{array}{l}\text { super_creative } \\
\text { core=1 }\end{array}$ & $-0,084$ & 0,012 & 0,048 & 0,022 & $0,230^{* * *}$ \\
\hline income & $-0,008$ & $0,045^{* * *}$ & $-0,065^{* * *}$ & $-0,009$ & 0,022 \\
$* * *$ - p-value $<0,05$ & & & & \\
\hline
\end{tabular}

As the results of regression analysis demonstrate, motivator as material stimulation (model 1), motivates younger people (the younger employee is, the stronger is connection). It can be explained by the fact that younger employees have not their material needs fully satisfied yet, that is shy material reward is better for them. The older the employee is the less effective is material stimulation.

Except age, extrinsic motivators connected with material rewards influence female employees more. It is obvious, that effective work over time it is definite social ladder for the female employees, which they are ready to use.

Additional material rewards effectively motivate people, who have permanent partner. It is possible to assume that this factor creates additional material needs, which need to be satisfied.

Consequently, positive extrinsic motivators effectively influence IT professionals, who find themselves in more complicated life situation, who have unsatisfied material needs. Analysis of regression coefficients demonstrates, that the most powerful influence such motivators have on people having families $(\mathrm{B}=0,257)$, females $(\mathrm{B}=0,145)$ and the youngest representatives of this professional group $(\mathrm{B}=0,008)$. When these characteristics match, the effectiveness of extrinsic motivators increase. It is significant to note, that the effectiveness of extrinsic motivators does not depend on professional position of IT employees.

Motivators of respect from the team and management (model 2) effectively influence young employees with good income, who perform creative work and take part in creation of new products. It is possible to assume, that these employees are targeted towards certain autonomy and independence in their activities to create new products themselves. Trust from the team and management are significant for them. That is why they are ready to work more productively and harder to gain this respect.

The strongest factor, which influence the effectiveness of this motivator is professional position of creative professional $(\mathrm{B}=0,116)$, the next is income $(\mathrm{B}=0,045)$. It is possible to assume that this type of motivator is more effective for the employees, who experience certain gap between income and their status in the company, when income is higher that their position.

The sense of responsibility as a type of intrinsic motivation (model 3), likely refers to the employees with lower income but part of creative professional group. Their attitude to work is responsible mostly because they like the work they do. Attitude from their co-workers is 
significant to them, they appreciate their authority for their teammates and they do not want to let their team down. The need for belongingness to the group is strong, they want to be part if the team. They are ready to work overtime doing the job, which others refuse to do, to feel that they are valuable part of the team. The strongest influence for this motivator is professional position of the employee. The employee does the job, which does not assume creation of new products and ideas, but the job requires responsibility for all working processes to function in order. If such employees do not get high salary, it means that they have high loyalty to the company. This loyalty to the company and to the team encourages them to do their job well.

It was already mentioned above, that the motivators such as threat of dismissal or bonus reduction, which are negative motivators, do not work in management of IT professionals. Regression analysis confirms this conclusion. IT professionals in Latvia are highly demanded professional group. There is high demand for IT professionals of Latvian labor market. They cannot be encouraged to perform more productively with threats and punishment.

Professional self-realization in a form of participation in complicated projects and solving interesting and challenging tasks (model 5) is very significant intrinsic motivator for IT professionals. This motivation works for satisfaction of need of self-actualization, which Maslow observed as one of the highest-level needs.

It is obvious that it is significant to combine various type of motivators for effective management of IT professionals depending on project and circumstances. In the situation, when it is necessary to complete complicated project fast, gain new ideas or vision, the manager can use intrinsic motivation, which allows professional to be proud of achievement, and extrinsic motivation as material reward or bonus. In the situation of additional routine work, which needs to be performed on a decent level, it is more sensible to use intrinsic motivation of sense of responsibility and extrinsic motivation of career perspective. This will mobilize employees loyal to the company and the team, and career-oriented employees. When management faces the case, where the tasks needs to be done in a short-term condition, it is correct to use intrinsic motivation directed towards authority promotion, approval from board members, combining it with responsibility for delay and possible negative consequences for the team in general.

It is significant to remember, that when managing IT professionals, it is not possible to use negative motivation approach, both intrinsic and extrinsic.

\section{Discussion}

The results of the research can be well interpreted with the help of McGregor Theory, who demonstrated that there is a need of combination of extrinsic and intrinsic motivators. Many scholars analyzed the influence of extrinsic and intrinsic motivation not only on labor productivity but also of satisfaction from work and retention of the employees. Similar findings from Deci and Ryan were described in "Cognitive Evaluation Theory», proving that autonomy becomes basic factor for individual motivation [1].

The research of Lowe, Levitt and Wilson [23], which was dedicated to management of generation $Y$, proved, that representatives of this generation need to work innovational, faster developing organization. Representatives of this generation are more often than others ready to quit their jobs, if they do not like the company, where they work. It is significant for them for company to have horizontal hierarchy structure, and for them to have an opportunity to get new knowledge.

London in his research of how employees [21] chose demonstrated that, when employees from generation $Y$ are satisfied with their job, have freedom of actions and certain autonomy, they do not want to leave their job to higher extent, than in situation, where they are motivated with extrinsic motivators but have lower satisfaction from the job. 
The research done in a framework of this paper demonstrates that IT professionals, most part of them are members of generation Y, are even more impatient towards negative extrinsic motivators. At the same time positive extrinsic motivators act locally, only in venerable situations and only in case of big gap between status and income, which happens extremely rarely.

The results of the research demonstrate that "carrot and stick" approach stops working in contemporary environment, especially in managing creative employees [24, 25]. Working place needs to be shaped in a way, that employee is involved in a process of production, that he feels responsibility, that company shares culture of trust, autonomy and respect. Intrinsic motivation becomes more significant that extrinsic motivation. This is essential change in management theory, which came from times of McGregor.

\section{Conclusion}

In contemporary world new global markets, new professions and new generations shape unique professional and labor culture. This culture requires new approaches of management of business and human resources. One of the biggest changes, which contemporary managers face, is change of attitude of employees to their work and change of their expectations from work.

The research done steadily demonstrates that for company managers, working in the market of Information technologies, it would be right to leave aside traditional conceptions of appraisal and punishment and about their part in management process.

Contemporary approaches to management should incline towards approach of influencing intrinsic motivation of the employees. In order for employees to perform more productively, they need to be motivated by significance of the tasks they perform, personal responsibility for the result of teamwork and the company in general, freedom and independence.

However, it is worth to remind, that the theories, which underlie intrinsic and extrinsic motivation, are still topical and reaching the balance between them can lead to success and grant company competitive advantage.

\section{References}

1. Ryan, R. M., Deci, E. L. (2000). Intrinsic and extrinsic motivations: Classic definitions and new directions. Contemporary Educational Psychology, 25(1), 54-67.

2. Bernstein, G. G., Cacioppo, J.T. (2000). Psychobiology and social psychology: Past, present, and future. Personality and social psychology review, 4(1), 3-15.

3. Crabtree, S. (2013). Worldwide, 13\% of employees are engaged at work. Retrieved from: http:/www.gallup.com/poll/165269/worldwide-employees-engaged-work.aspx

4. Taylor, F.W. (1911). The principles of scientific management. New York: Harper and Brothers.

5. Mayo, E. (1933). The human problems of industrial civilization. New York: Macmillan.

6. Perry-Smith, J.E., Shalley, C.E. (2003). The Social Side of Creativity: a Static and Dynamic Social Network Perspective. Academy of Management Review, 28(1), 89-106.

7. Maslow, A. (1954). Personality and motivation. New York: Harper.

8. McClean, E., Collins, C.J. (2019). Expanding the concept of fit in strategic human resource management: An examination of the relationship between human resource practices and charismatic leadership on organizational outcomes. Human Resource Management, 58(2), 187-202. [CrossRef] 
9. Hitka, M., Kozubíková, L., Potkány, M. (2018). Education and gender-based differences in employee motivation. Journal of Business Economics and Management, 19(1), 80-95. [CrossRef]

10. Soroa, G.G., Balluerka, N., Hommel, B., Aritzeta, A. (2015). Assessing interactions between cognition, emotion, and motivation in creativity: The construction and validation of EDICOS. Thinking Skills and Creativity, 17, 45-58.

11. Hofstede, G. (1984). The cultural relativity of the quality of life concept. Academy of Management Review, 9(3), 389-98.

12. Cianci, R., Gambrel, P. (2003). Maslow's hierarchy of needs: Does it apply in a collectivist culture. Journal of Applied Management and Entrepreneurship, 8(2), 14361.

13. Tay, L., Diener, Ed. (2011). Needs and subjective well-being around the world. Journal of Personality and Social Psychology, 101(2), 354-65.

14. McGregor, D. (1960). The human side of enterprise. New York: McGraw-Hill

15. Vroom, V.H. (1964). Work and motivation. Oxford, UK: Wiley.

16. Lu, X., Wu, J. (2013). Effects of extrinsic and intrinsic motivators on using utilitarian, hedonic, and dual-purposed information systems: A meta-analysis. Journal of the Association for Information Systems, 14(3), 153-91.

17. Kuvaas, B., Buch, R., Gagné, M.,Dysvik, A. (2016). Do you get what you pay for? Sales incentives and implications for motivation and changes in turnover intention and work effort. Motivation and Emotion, 40(5), 667-80.

18. Iqbal, A. (2019). The strategic human resource management approaches and organisational performance: The mediating role of creative climate. Journal of Advances in Management Research, 16(2), 181-93. [CrossRef].

19. Story P., Stasson M., Mahoney J., Hart J. (2008). A two-factor model of achievement motivation. Social Behavior \& Personality: An International Journal, 36(5), 707-18.

20. Deci, Ed.L., Ryan, R.M. (1985). Intrinsic Motivation and Self-determination in Human Behavior. New York: Plenium.

21. London, A. (2009). The impact of intrinsic and extrinsic motivation on job choice in Generation Y. Paper presented at 4th Annual Siena College Student Conference in Business. Retrieved from: http://66.194.176.99/uploadedfiles/home/academics /schools_and_departments/school_o

22. Cooper, R.B., Jayatilaka, B. (2006). Group creativity: The effects of extrinsic, intrinsic, and obligation motivations. Creativity Research Journal, 18(2), 153-172.

23. Lowe, D., Levitt, K. J., Wilson, T. (2008). Solutions for Retaining Generation Y Employees in the Workplace. Business Renaissance Quarterly,.

24. Stachova, K., Stacho, Z., Blstakova, J., Hlatká, M., Kapustina, L.M. (2018). Motivation of employees for creativity as a form of support to manage innovation processes in transportation-logistics companies. Nase More, 65, 180-6. [CrossRef]

25. Jankelová, N., Joniaková, Z., Blštáková, J., Némethová, I. (2017). Readiness of human resource departments of agricultural enterprises for implementation of the new roles of human resource professionals. Agricultural Economics-Zemnedelska Ekonomika, 63(10), 461-70. 